\title{
Franco-Japanese and other collaborative contributions to understanding chimpanzee culture at Bossou and the Nimba Mountains
}

Tatyana Humle 1,*

Phone 01227827845

Email T.Humle@kent.ac.uk

1 Durrell Institute of Conservation and Ecology, School of Anthropology and Conservation, University of Kent, Canterbury, CT2 7NR UK

\section{Abstract}

The Japanese approach to science has permitted theoretical leaps in our understanding of culture in non-human animals and challenged human uniqueness, as it is not embedded in the Western traditional dualisms of human/animal and nature/culture. This paper highlights the value of an interdisciplinary approach and combining methodological approaches in exploring putative cultural variation among chimpanzees. I focus particularly on driver ants (Dorylus sp.) and oil palm (Elaeis guineensis) consumption among the Bossou and Nimba chimpanzees, in southeastern Guinea at the border with Côte d'Ivoire and Liberia, and hand use across different tool use tasks commonly witnessed at Bossou, i.e. ant-dipping, nut-cracking, pestle-pounding, and algae-scooping. Observed variation in resource use was addressed across differing scales exploring both within- and between-community differences. Our findings have highlighted a tight interplay between ecology, social dynamics and culture, and between social and individual learning and maternal contribution to tool-use acquisition. Exploration of hand use by chimpanzees revealed no evidence for individual-level hand or community-level task specialisation. However, more complex types of tool use such as nut-cracking showed distinct lateralization, while the equivalent of a haptic manual action revealed a strong right hand bias. The data also suggest an overall population tendency for a right hand 
preference. As well as describing these sites' key contributions to our understanding of chimpanzees and to challenging our perceptions of human uniqueness, this paper also highlights the critical condition and high levels of threats facing this emblematic chimpanzee population, and several questions that remain to be addressed. In the spirit of the Japanese approach to science, I recommend that an interdisciplinary and collaborative research approach can best help us to challenge perceptions of human uniqueness and to further our understanding of chimpanzee behavioural and social flexibility in the face of local social, ecological and anthropogenic changes and threats to their survival.

\section{Keywords}
Handedness
Tool use
Oil palm
Driver ants
Social learning
Coexistence
Conservation

\section{Bossou and the Nimba Mountains, Guinea: the links with France and Japan}

\section{From the early days of Bossou to the present day}

Bossou was originally discovered as an important chimpanzee field site over 70 years ago, by the French Zoologist Prof. Maxime Lamotte (Kortlandt 1986). Prof. Adrian Kortlandt, a Dutch primatologist, later visited Bossou briefly several times during the early $1960 \mathrm{~s}$; he was the first to conduct research on this chimpanzee community, during which time his team experimentally video-recorded chimpanzees' response to a stuffed leopard (Kortlandt 1962). It was not until 1976 that Bossou was established as a long-term field site for the study of chimpanzees (Pan troglodytes verus) under the auspices of the Kyoto University Primate Research Institute, (KUPRI), Japan (Sugiyama and Koman 1979a, b; Sugiyama 1981). A detailed research programme at Bossou was established by Prof. Sugiyama in 1976 and by Prof. Matsuzawa in 1986, continued by their respective teams of students and national and 
international collaborators (Table 1) (Matsuzawa et al. 2011). Field research at Bossou has been relatively continuous since 1995, although the Ebola epidemic which began late 2013 has recently dramatically reduced research and conservation efforts in situ.

\section{Table 1}

Key dates of the history of research at Bossou and events marking the Bossou chimpanzee community

\begin{tabular}{|c|c|}
\hline $\begin{array}{l}\text { Key } \\
\text { dates }\end{array}$ & Event \\
\hline 1942 & $\begin{array}{l}\text { The French Zoologist Prof. Maxime Lamotte notes the value of Bossou } \\
\text { as potentially an important field site for the study of wild chimpanzees }\end{array}$ \\
\hline $\begin{array}{l}\text { Early } \\
1960 \mathrm{~s}\end{array}$ & $\begin{array}{l}\text { Adrian Kortlandt begins study of Bossou chimpanzees and runs anti- } \\
\text { predatory field experiments using stuffed leopard }\end{array}$ \\
\hline 1976 & $\begin{array}{l}\text { Prof. Yukimaru Sugiyama starts the long-term research on wild } \\
\text { chimpanzees of Bossou }\end{array}$ \\
\hline 1980 & $\begin{array}{l}\text { The Guinean portion of the massif is declared a Biosphere Reserve, } \\
\text { extending over } 21,910 \text { ha, comprising of a large portion of the Nimba } \\
\text { range (with the exception of an area designated for mining) and the } \\
\text { Bossou and Déré ecosystems }\end{array}$ \\
\hline $\begin{array}{l}1986- \\
1989\end{array}$ & $\begin{array}{l}\text { Prof. Matsuzawa and his team start the longitudinal study of nut- } \\
\text { cracking behaviour using field experiments in the outdoor laboratory at } \\
\text { the top of Gban }\end{array}$ \\
\hline $\begin{array}{l}\text { End } \\
1980 \text { s }\end{array}$ & $\begin{array}{l}\text { The first cohort of Japanese post-graduate students pursue research at } \\
\text { Bossou }\end{array}$ \\
\hline 1995 & $\begin{array}{l}\text { Beginning of the internationalization of Bossou Research Project and } \\
\text { first rainy season follow of the chimpanzees }\end{array}$ \\
\hline 2001 & $\begin{array}{l}\text { Creation of the Institut de Recherche Environnementale de Bossou } \\
\text { (IREB)-Guinean Research Counterparts at Bossou to the Kyoto } \\
\text { University Primate Research Institute }\end{array}$ \\
\hline $\begin{array}{l}2003- \\
2004\end{array}$ & $\begin{array}{l}\text { Major respiratory epidemic which results in a significant demographic } \\
\text { decline in the Bossou chimpanzee community }\end{array}$ \\
\hline $\begin{array}{l}\text { Dec. } \\
2013\end{array}$ & $\begin{array}{l}\text { The Ebola epidemic starts in the forest region of Guinea and has a } \\
\text { devastating impact on people in the region; no indication or evidence } \\
\text { that wild chimpanzees are affected }\end{array}$ \\
\hline
\end{tabular}

\section{The early expeditions of Prof. Maxime Lamotte and the Nimba mountains}

In 1942, Prof. Maxime Lamotte led an expedition to the Nimba Mountains, 
$6 \mathrm{~km}$ away from Bossou, aiming to explore the geographical and wildlife diversity of the massif on its Guinean side (Leclerc et al. 1955) (Fig. 1; Table 2). Lamotte pursued research on the fauna and flora of the Nimba Mountains for nearly two decades, and contributed a wealth of knowledge of the unique biodiversity and ecosystems present across this mountainous landscape which spans three countries: Guinea, Côte d'Ivoire and Liberia (Heim de Balsac and Lamotte 1958; Leclerc et al. 1955; Mollard et al. 1955; Angel et al. 1954a, b).

Fig. 1

Map of Bossou and the Nimba Mountains
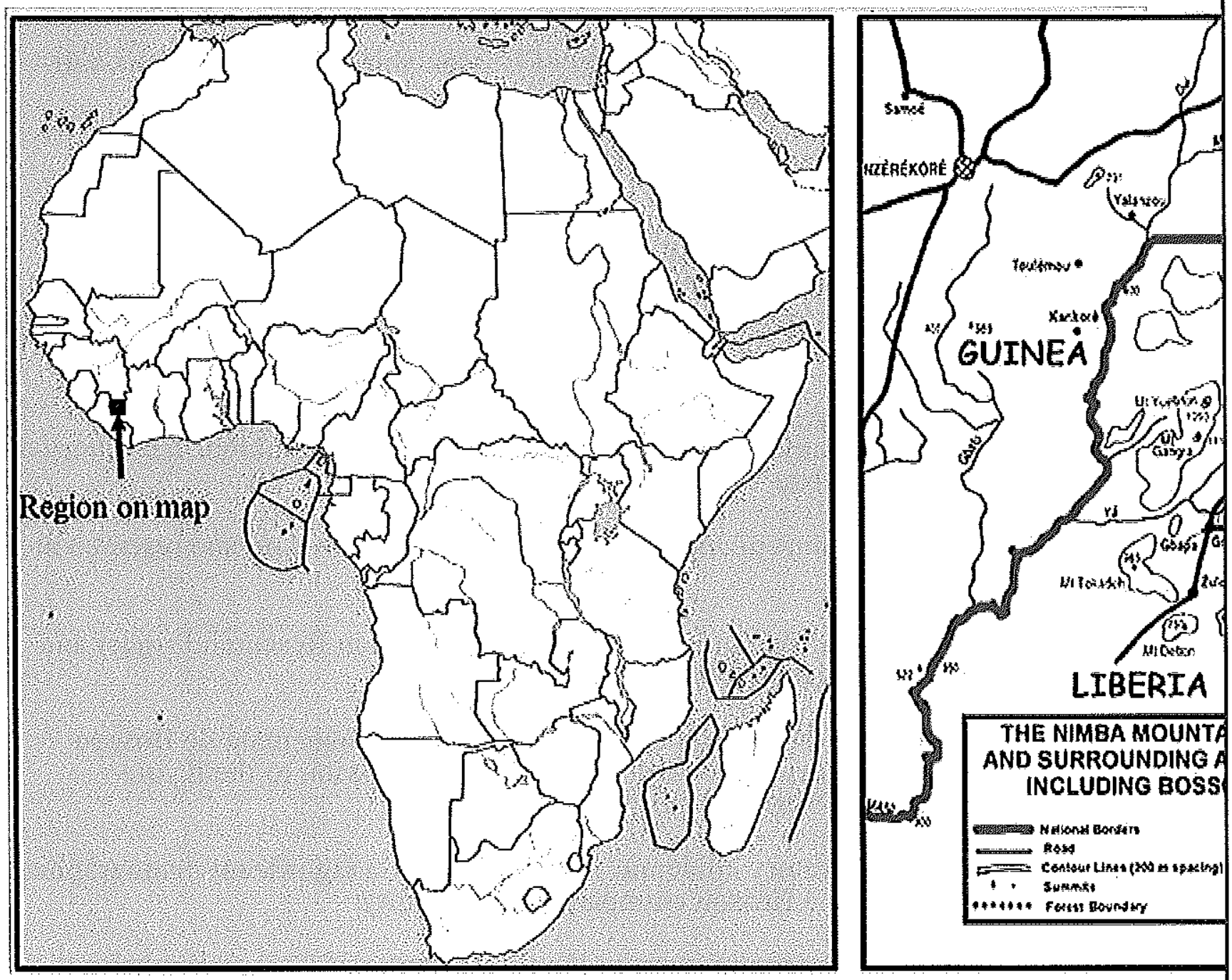

Table 2

Key dates of the history of research and protection status of the Nimba Mountains and surrounding areas

\begin{tabular}{|l|l|}
\hline Key dates & Event \\
\hline 1942 & $\begin{array}{l}\text { Prof. Maxime Lamotte leads an expedition to the Nimba } \\
\text { Mountains to explore the geographical and wildlife diversity of }\end{array}$ \\
\hline
\end{tabular}


the massif on its Guinean side

The French colonial administration establishes the Nimba

$1943-1944$ mountains as a Nature Reserve, the "Réserve Naturelle Intégrale du Mont Nimba", in 1943 in Côte d'Ivoire, and in 1944 in Guinea

1951

$1970 \mathrm{~s} / 1980 \mathrm{~s}$

J. Richard Molard loses his life in an accident in Nimba

Prof. Yukimaru Sugiyama surveys forest around Seringabara and Gouela

The Guinean portion of the massif is declared a Biosphere

1980

Early 1990s

$1993-1994$

1999

$1999-2004$

Reserve, extending over 21,910 ha, comprising of a large portion of the Nimba range (with the exception of an area designated for mining) and the Bossou and Déré ecosystems

Dr. Frederique Joulian conducts surveys in Yealé, Côte d'Tvoire to locate nut species and cracking sites

Prof. Tetsuro Matsuzawa and Prof. Gen Yamakoshi visit Yealé site

Dr. Makoto Shimada resumes brief survey around Seringbara and Gouéla, Guinea

Dr. Tatyana Humle conducts research concurrently at Yealé, Côte d'Ivoire, and Seringbara, Guinea

2004

2009-2011

Dec. 2013

Dr. Kathelijne Koops and collaborators implement more continuous research in the Seringbara region of the massif

Dr. Nicola Granier conducts research on the Côte d'Ivoire side of the Nimba range

The Ebola epidemic starts in the forest region of Guinea and has a devastating impact on people in the region; no indication or evidence that wild chimpanzees are affected

As a result of these research endeavours and in recognition of their biological diversity, unique ecology and exceptional scenic beauty, the Nimba Mountains were established as a Nature Reserve, the "Réserve Naturelle Intégrale du Mont Nimba", in 1943 in Côte d'Ivoire, and in 1944 in Guinea by the French colonial administration. The reserve extends over 12,700 ha on the Guinean side and 5,000 ha on the Côte d'Ivoire side. Both reserves now form a World Heritage Site, gazetted in 1981 for Guinea and in 1982 for Côte d'Ivoire. The Guinean portion of the massif was declared a Biosphere Reserve in 1980 , extending over 21,910 ha, comprising a large portion of the Nimba range (with the exception of an area designated for mining and currently targeted for exploitation) and the Bossou and Déré ecosystems (Matsuzawa et al. 2011) (Fig. 1). 
Before 1999, little information was available about the chimpanzee population in the Nimba Mountains region of Guinea (Boesch et al. 1994; Matsuzawa and Yamakoshi 1996; Sugiyama 1995, 1981) (Table 2). Sugiyama visited the village of Seringbara at the foothills of the Nimba Mountains several times starting in 1976. He interviewed the villagers, and conducted two surveys of the forest surrounding the village in order to determine the presence of chimpanzees in the area. He concluded that the chimpanzees were only seasonally transient in the region (Sugiyama 1981). However, over 70 nests and numerous feeding remains of chimpanzees were discovered in 1999 in the forest beside the village, and vocalizations of chimpanzees were regularly heard (Shimada 2000). These findings suggested the presence of a resident group near Seringbara, which has since been confirmed (Humle 2003; Koops et al. 2004).

Biomonitoring and progressive habituation of chimpanzees in the Seringbara area has been ongoing since 1999, with research focused especially on the relationship between ecology and elementary technology (Koops et al. 2008; Koops et al. 2015b).

Our understanding of chimpanzee behaviour on the Côte d'Ivoire side of the massif began when Dr. Frederique Joulian, as a member of a survey team investigating the distribution of nut-cracking behaviour in Côte d'Ivoire (Boesch et al. 1994), conducted a preliminary study beside Yealé near the Nuon River at the foothills of the Nimba Mountains. The village of Yealé is located $12 \mathrm{~km}$ southeast of Bossou on the Côte d'Ivoire side of the Nimba Mountains (Fig. 1). Boesch et al. (1994) found two Coulacracking sites in the area, but were cautious about attributing these sites to chimpanzees as human presence had been confirmed, and the local people (Yacouba and Manon) are also known to crack and consume this species of nut. Joulian also confirmed the presence of Panda oleosa, Parinari excelsa and Detarium senegalensis trees on this side of the massif (Joulian 1994); these species are cracked and consumed by chimpanzees in the Taï National Park, approximately $200 \mathrm{~km}$ away (Boesch and Boesch 1983). In December 1993 and January 1994, Matsuzawa and Yamakoshi (1996) conducted two brief surveys of Nimba chimpanzees in the area of the Nuon River. More systematic research around Yealé was carried out between 1999 and 2001 (Humle and Matsuzawa 2001, 2004) and 2009 and 2011 (Granier et al. 2014) (Table 2). These more recent studies and surveys by 
KUPRI International researchers and students not only confirmed the occurrence of nut-cracking for Coula nuts, but also for oil palm (Elaeis guineensis) nuts in the area, albeit at low frequencies (Shimada 2000; Humle and Matsuzawa 2001, 2004).

Finally, these Franco-Japanese efforts in collaboration with Guinean and other national and international collaborators have highlighted the necessity for transboundary preservation of the Nimba massif as a single ecosystem complex, because like many other species with large home ranges, chimpanzees use the forest and the high altitude savanna without any concern for national boundaries. In addition, like other vertebrate communities in tropical regions (Gauthier-Hion et al. 1985), Nimba chimpanzees play an important role in dispersing the seeds of numerous plant species, thus contributing to the botanical diversity and richness of the massif which encompasses many endemic species (Adam 1981).

\section{The bridging of two traditions and methodological approaches}

The Japanese approach to science has permitted theoretical leaps in our understanding of culture in non-human animals and it has challenged human uniqueness, as it is not embedded in the Western traditional dualisms of human/animal and nature/culture and is generally more inductive than deductive (de Waal 2001; Nakamura and Nishida 2006). Such an inductive approach tends to be less biased, as it depends on observing and then interpreting data, as opposed to the typical western approach that is cemented in a framework of systematically gathering data to dispel or support a priori articulated hypotheses. An important step in bridging these approaches and drawing attention to early Japanese contributions to the study of non-human primates was Imanishi's launch of the first ever scientific journal in English dedicated to Primatology, Primates, in 1957; six years before the emergence of Folia Primatologica, the first western journal uniquely dedicated to non-human primates. Later, Prof. Matsuzawa saw the value in promoting exchanges and collaboration among budding or established primatologists from Japan and the West. In this context, I was fortunate enough in 1995 to have the opportunity to be the first French national and non-Japanese student to set foot at Bossou, one of the two long-term chimpanzee field sites run by the University of Kyoto (the other being at Mahale in Tanzania, established by Prof. Toshisada Nishida). 
The non-dualistic perception of nature embedded in Japanese philosophy and the Japanese primatological tradition (de Waal 2001) also underpins the longevity and conservation commitment of Japanese research at Bossou. Indeed, compared to chimpanzees at other long-term field sites, Bossou chimpanzees are often perceived as unusual due to their close coexistence with villagers and to their semi-isolation from neighbouring chimpanzees only $6 \mathrm{~km}$ away in the Nimba Mountains. Nevertheless, Japanese primatologists such as Sugiyama and Matsuzawa clearly saw the value in studying wild chimpanzees in such a unique anthropogenic setting in which local human culture and traditional beliefs help to sustain a harmonious coexistence between people and chimpanzees.

The Bossou site has distinctly promoted our understanding of the behaviour and ecology of wild chimpanzees, in particular their ability to make and use tools, and their adaptation to sharing the landscape with people (Matsuzawa et al. 2011). Since the late 1980s, research at Bossou has also paved the way in terms of innovative approaches to studying chimpanzees in their natural habitat: Matsuzawa and his team introduced longitudinal video recording and field experimental approaches to the study of behaviour and cognition (Humle and Newton-Fisher 2013; Matsuzawa et al. 2011). Open to the idea of challenging supposed hallmarks of human uniqueness, I adopted such methodological approaches in my own research. During these early days in Bossou, careful observations and video-recording of the chimpanzees led me to pose several key questions focused on non-human culture and handedness: Why is there such a great deal of variation in how Bossou chimpanzees perform ant-dipping? To what extent do the Bossou chimpanzees rely on the oil palm for nesting as well as feeding? Do the neighbouring Nimba chimpanzees utilise the oil palms available in their range the same way as Bossou chimpanzees do? If not, do proximate ecological variables constrain usage? What does this mean for behavioural transmission within and between communities? How does tool use complexity influence hand use and is there such a thing as hand- or task specialisation in chimpanzees?

\section{Insights generated}

\section{Culture and ecology}


Microecological scale: combining entomology, field experiments and observations

Why and when do Bossou chimpanzees use shorter versus longer tools and one technique over another to harvest driver ants? The first challenge was to identify the different species of driver ants consumed by Bossou chimpanzees, including their diversity and availability. Collaboration with a driver ant specialist, Dr. Caspar Schöning, allowed us to determine the taxonomy of the species targeted by chimpanzees during ant dipping episodes; these included five species, three epigaeic and two intermediate species; these two types of Dorylus sp. differ greatly in their behaviours (Schoning et al. 2008). Epigaeic species form large conspicuous hunting swarms on the ground and up in the vegetation, while intermediate species hunt only on the ground in leaf litter. Whereas workers of the epigaeic species attack and bite when disturbed, workers of intermediate species tend to withdraw into tunnels underground or into the leaf litter. This taxonomic level of analysis allowed us to discern different responses to disturbance and biting risk posed by each species based on mandibular length and their lifestyle. The next challenge was to establish the chimpanzee perspective and assess yield during ant-dipping bouts across the different species, different tool lengths, dipping times and conditions under which chimpanzees ant-dip, i.e., at the ants' nest site or while they are moving on the ground, for example when migrating or hunting for prey. For this, we used methods inspired by Matsuzawa's hallmark combination of utilising long-term video records and an experimental approach, to gather detailed information on how and why Bossou chimpanzees ant-dip the way they do. We performed a series of in situ experiments involving humans dipping for ants and video-recorded the details and harvesting of ants captured along the tool to quantify yield (Mobius et al. 2008). In parallel, all chimpanzee ant-dipping sessions were video recorded on an ad libitum basis (Humle and Matsuzawa 2002).

These three complementary approaches provided us with enormous insights into ant-dipping in the chimpanzees of Bossou. Our results suggested that the chimpanzees adjust their behaviour by positioning themselves off the ground to minimise risk of getting bitten especially when dipping at nest sites or on the species more likely to attack and inflict more pain (Humle 2010; Humle and Matsuzawa 2002) (Fig. 2). The video data also revealed that the chimpanzees used longer tools when dipping at nests, especially when targeting epigaeic species, and when greater ant 
density poses a greater risk to the dipper (Humle and Matsuzawa 2002). The experimental data showed that in such contexts the use of longer tools also increased dipping efficiency (Humle 2003). In addition, there was a strong relationship between tool length and technique employed. Short tools ( $<50 \mathrm{~cm}$ long) were solely associated with direct mouthing, whereby the tools is brought directly to the mouth for consuming the harvested ants. Longer tools, typically more than $50 \mathrm{~cm}$, were associated with the pull through technique, which involves swiping of the hand along the tool to bring the harvested ants to the mouth (Humle and Matsuzawa 2002). These findings highlighted a tight interplay between ecology and culture, which has received corroboration from analysis of ant-dipping at other chimpanzee study sites across Africa (Koops et al. 2015a; Mobius et al. 2008; Schoning et al. 2008; Koops et al. 2015b).

\section{Fig. 2}

Diagram illustrating the main factors affecting ant-dipping position, tool length and technique used in chimpanzees with illustrative photos

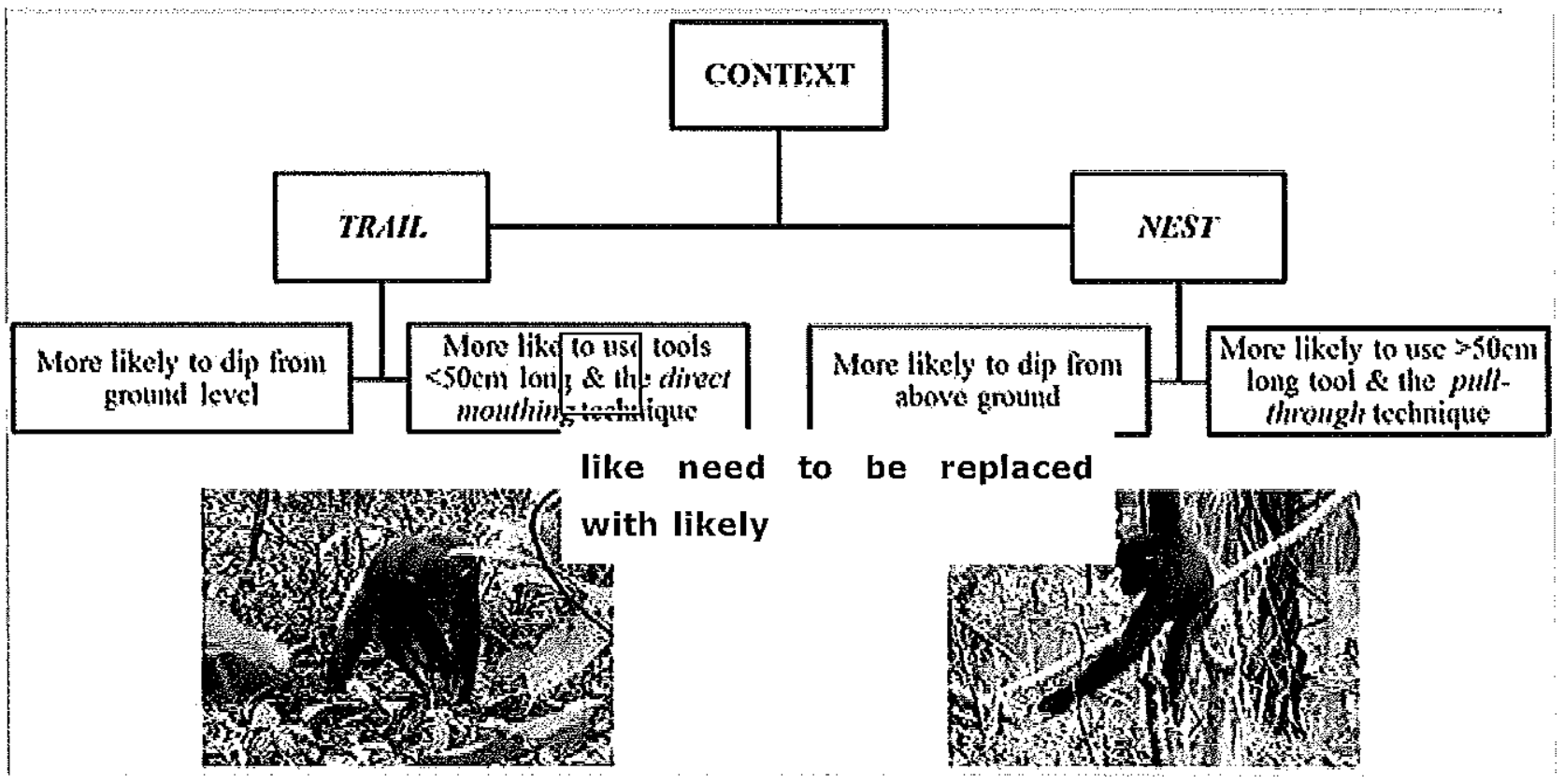

Macroecological scale: surveying opportunity

An ecological approach to the study of behavioural variation among wild chimpanzees can provide important insights into the relationships between environmental parameters and behaviour, and shed light on variables that may reflect underlying cultural influences on behaviour (McGrew 1992). Such an approach has been successfully applied to explore variations in chimpanzees' feeding behaviour (Nishida et al. 1983), tool-use (Boesch et 
al. 1994; Collins and McGrew 1988, 1987; McGrew 1979; McGrew et al. 1997; Uehara 1982) and nesting behaviour (Baldwin et al. 1981; Koops et al. 2007). An ecological approach to inter-community variation in behaviour was also used to compare the use of the oil-palm tree (Elaeis guineensis) between Bossou chimpanzees and the neighbouring communities around Seringbara and Yealé, in the Nimba Mountains. We first aimed to establish the extent to which Bossou chimpanzees rely on the oil palm and indirect indicators of oil palm use, before proceeding to examine if, how and when the neighbouring Nimba chimpanzees utilised available oil palms in their range, and any proximate ecological variables constraining potential usage.

The oil palm (Elaeis guineensis) is one the most valuable and important fallback foods for Bossou chimpanzees (Yamakoshi 1998); it provides them with year-round food sources including the rich mesocarp of the fruit, the oily nut kernel, the petiole of young palm fronds, the base of immature flowers, the pith of mature leaves and the sugary and nutritious palm heart (Yamakoshi and Sugiyama 1995; Humle and Matsuzawa 2004). Focal behavioural data from 2003 to 2004 revealed that Bossou chimpanzees spent nearly a quarter $(23.9 \%)$ of their feeding time consuming oil palm parts. In addition the oil palm is a highly preferred nesting species for Bossou chimpanzees: between 1999 and 2001, 30\% of all night nests recorded occurred in oil palms (Humle 2003). As the oil palm is common in many chimpanzee habitats across Africa and in light of its role as a keystone food and nesting resource for the Bossou chimpanzees, it was logical to investigate comparable usage in neighbouring communities.

Humle and Matsuzawa (2004) assessed oil palm density in the home ranges of the Bossou, Seringbara and Yealé chimpanzees by performing vegetation transects. In addition, we monitored a representative sample of oil palms for signs of use, raw material and nut availability for nutcracking, and monthly phenology to estimate frond, flower and fruit availability. Our methods were based on those used by McGrew et al. (1997) to explore why chimpanzees in the Lope Reserve in Gabon do not crack nuts. Oil palm use varied significantly across our study sites (Table 3 ). We failed to identify proximate environmental variables that could account for the observed variations in frequency of specific types of use across the three sites, although oil palm density was significantly lower in Seringbara, where signs of use are limited to indirect evidence of fruit in 
the chimpanzees' faeces (Koops pers. comm.). Ohashi (2015) contributed new information on oil palm use by chimpanzees in Liberia, over $50 \mathrm{~km}$ away from Bossou. Around the village of Kpala, he recorded pestlepounding, which was previously thought to be unique to Bossou, as well as other types of usages similar to those seen Bossou, including nut-cracking and petiole feeding (Table 3 ). Assuming migration between these communities in the recent past (Shimada et al. 2004) and the role of social learning in the intra-community transmission of some these uses (based on studies of nut-cracking at Bossou: Inoue-Nakamura and Matsuzawa 1997), these results raise interesting questions about diffusion of behaviour between chimpanzee communities. For example, how do local social and environmental conditions affect the transmission of cultural behaviours between communities? How do patterns of social interaction and the communities' feeding ecology and ranging behaviour affect the dynamics of and opportunities for transmission?

\section{Table 3}

Summary of the use of the oil-palm as a food resource and for nesting at Bossou an chimpanzee communities

\begin{tabular}{|c|c|c|c|c|c|c|c|}
\hline & $\begin{array}{l}\text { Oil palms } \\
\text { per } \mathrm{km}^{2} \\
\text { (excluding } \\
\text { cultivated } \\
\text { fields) }\end{array}$ & Nest & $\begin{array}{l}\text { Nut (nut- } \\
\text { cracking) }\end{array}$ & Fruit & $\begin{array}{l}\text { Petiole } \\
\text { of } \\
\text { young } \\
\text { frond }\end{array}$ & Flower & $\begin{array}{l}\text { Palm } \\
\text { Heart } \\
\text { (Pestle. } \\
\text { Poundi }\end{array}$ \\
\hline $\begin{array}{l}\text { Bossou, } \\
\text { Guinea }\end{array}$ & $\begin{array}{l}\text { Abundant } \\
(7.2)\end{array}$ & $\checkmark$ & $\checkmark$ & $\checkmark$ & $\checkmark$ & $\checkmark$ & $\checkmark$ \\
\hline $\begin{array}{l}\text { Seringbara, } \\
\text { Guinea* }\end{array}$ & $\begin{array}{l}\text { Present, } \\
\text { Patchy } \\
(<1)\end{array}$ & & & $\checkmark$ & & & \\
\hline $\begin{array}{l}\text { Yealé, } \\
\text { Côte } \\
\text { d'Ivoire }\end{array}$ & $\begin{array}{l}\text { Present, } \\
\text { Patchy } \\
(4.2)\end{array}$ & $\checkmark$ & $\checkmark$ & $\checkmark$ & $\checkmark$ & & \\
\hline $\begin{array}{l}\text { Kpala, } \\
\text { Liberia** }\end{array}$ & Abundant & & $\checkmark$ & $\checkmark$ & $\checkmark$ & & $\checkmark$ \\
\hline
\end{tabular}

Adapted from Humle and Matsuzawa (2004)

* Koops pers. obs

** Ohashi (2015) and pers. comm 
Many of these questions are yet to be addressed in situ. However, continued habituation of the Nimba chimpanzees and increased knowledge of the demographics, the ecology and behaviour of other chimpanzee communities in the region will no doubt further our understanding of their feeding behaviour, nesting, ranging patterns and social structure, and how these may influence variations in oil palm use and reliance on subsistence tool use behaviours such as nut-cracking and pestle-pounding (Ohashi 2015 ). Future studies may also allow us to detect the presence of chimpanzees originally native to Bossou, either via genetic means or direct observation, and to appreciate past and future dispersal patterns between these communities, helping us to better understand patterns of transmission and constrains acting at the community level.

\section{Tool use acquisition and social influences}

The results of our work on the acquisition of ant-dipping skills suggests that social learning and individual learning may act in concert, allowing efficiency in performance and flexibility in behaviour in the face of variable conditions and exposure to risk (Humle et al. 2009). This study confirmed that for the first five years of a chimpanzee's life, the mother acts as the prime model, with accessibility and exposure to other social models increasing post-weaning. Although dipping at nests supplies a greater yield per unit of time than dipping at trails, mothers with unweaned young dipped significantly more frequently at trails than at nests. Whether intentional or not, all mothers therefore provided their offspring with less hazardous conditions in which to observe and practice ant-dipping.

In addition, we found that mothers differed greatly in time spent antdipping. Those young whose mothers spent more time ant-dipping (highopportunity young), started observing ant dipping sooner than young whose mothers dipped less often (low-opportunity young). Highopportunity young also acquired ant dipping skills earlier than lowopportunity young. Learning opportunity also influenced dipping success and proficiency: young with greater learning opportunity committed fewer dipping errors (dips yielding no ants), especially during their formative years (between two and six years old). Dip duration was used as a measure of proficiency (i.e., the number of ants gathered per dip), as in our human ant-dipping experiments this measure correlated well with greater yield regardless of the ants' lifestyle or condition (Mobius et al. 2008). Young 
between 5 and 10 years of age with greater learning opportunity demonstrated longer dip durations than low-opportunity young. Finally, the mother's proficiency and time spent ant dipping correlated positively with those of their unweaned offspring $(<5$ years old).

However, mothers and offspring did not match in tool length, although there was a trend for young with high learning opportunity to match their mother's tool length more closely than other young. Only one mother in our study ever exhibited the pull-through technique when using tools more than $50 \mathrm{~cm}$ long, whereas all young more than 5 years old and all adult males were observed to employ this technique. Young, therefore, did not acquire this technique by observing their mothers. Young between 5 and 10 years old experienced $61.8 \%(59 / 86)$ of their ant-dipping sessions in the presence of ant-dipping members of the community other than their mother, and thus they had ample opportunity to watch others employ the pull-through technique with tools more than $50 \mathrm{~cm}$ long (Humle and Matsuzawa 2002). Therefore it is possible that young acquired this technique by observing others. Our findings clearly show that mothers facilitate the learning opportunities for their offspring, thus influencing their ant-dipping acquisition and performance. This approach to exploring the development and socially-biased learning of tool use behaviour was inspired by Inoue-Nakamura and Matsuzawa's (1987) work on the development of nut-cracking behaviour among Bossou chimpanzees in an outdoor laboratory setting within the chimpanzees' core home range. Our approach was also influenced by later studies at Bossou by Biro and colleagues (Biro et al. 2010) exploring the concept of master-byapprenticeship model, whereby the apprentice acquires the skill through repeated observations of the master, a process favoured by the high levels of tolerance by the master and the appentice's strong intrinsic motivation to copy the master (Matsuzawa et al. 2001). All these studies similarly involved unbiased, detailed, cross-sectional and longitudinal video recording of chimpanzee behaviour.

\section{Hand use and laterality}

Few studies have provided handedness data across multiple manual tasks in wild chimpanzees (Boesch 1991; Marchant and McGrew 1996; McGrew and Marchant 2001; Sugiyama et al. 1993). Right-hand specialisation is another hallmark of our species (Marchant et al. 1995; 
Warren 1980) and studies of non-human animals have sought to shed light on the evolutionary origins of this significant human characteristic. In this context Bossou has yielded valuable information on individual- and community-level patterns of laterality in hand-use (Sugiyama et al. 1993; Sousa et al. 2009; Humle and Matsuzawa 2009). Individual laterality in hand-use among adult Bossou chimpanzees ( $>11$ years old) was incongruent between tool-use tasks (Fig. $3 \mathrm{a}$ ); indeed, no evidence for hand specialisation emerged, and at the community-level, there was also no strong evidence for task specialisation (Fig. 3 b) (Humle and Matsuzawa 2009). However, our findings confirmed the hypothesis that complex behaviours involving a hierarchical structure of actions or object associations, such as observed during bimanual processing or nut-cracking, are associated with higher levels of laterality in hand use (Fig. $3 \mathrm{c}$ ). The data also suggested that haptic tasks, e.g. when the chimpanzees blindly insert their hand and arm into a hole to retrieve the oil palm heart during pestle pounding, may have played an important evolutionary role in driving right population-level handedness (Fig. 3b), as previously suggested by Lacreuse et al. (1999) in study of captive chimpanzees. Although it is generally recognised that chimpanzee handedness is weaker than in humans, Humle and Matsuzawa (2009) highlighted a tendency for a community-level right-hand bias (Fig. 3 b) concordant with findings emerging from indirect data on handedness in early hominids (Toth 1985). However, the individual-level incongruence in hand-use lateralization across tasks elicits interesting new questions: how does handedness develop and what factors influence this development? Are more lateralised individuals more efficient? More data will be needed to address such questions; the Bossou community is unfortunately too small to address these comprehensively; therefore, longitudinal data from multiple sites and manual tasks are urgently needed.

\section{Fig. 3}

a Individual handedness index scores across four tool-use behaviours, in addition to manual extraction of palm heart among Bossou adult chimpanzees ( $>11$ years old). Note: male name are capitalized; Fana has a dislocated shoulder explaining the $100 \%$ right-hand bias. b Mean handedness score ( \pm SE) across behaviours among adult Bossou chimpanzees ( $>11$ years old), excluding Fana. c) Mean absolute handedness score $( \pm \mathrm{SE})$ across behaviours among adult Bossou chimpanzees ( $>11$ years old), excluding Fana 


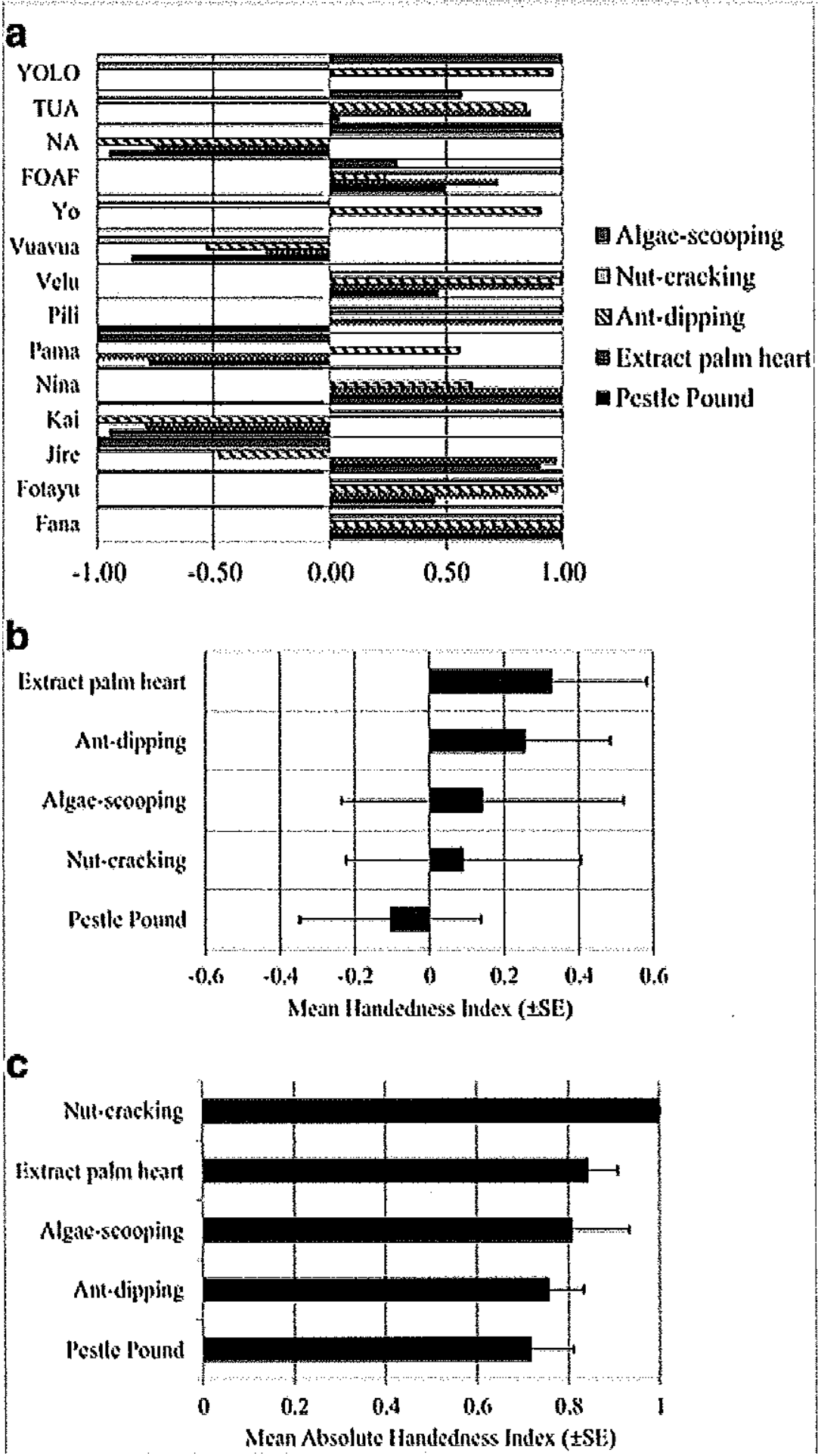

\section{What does the future hold?}

By embracing a Japanese approach and hybridising it with a more deductive western approach, I learnt to query variation across different scales (i.e. within the Bossou community on a micro-level and more regionally across both neighbouring and more distant sites), and to value the importance of inter-disciplinarity and combining methodological approaches in contributing to knowledge, especially the value of field experiments and longitudinal recording for behavioural sampling. However, as highlighted above, many questions remain to be addressed 
and sadly, the Bossou community has hit a critical demographic threshold, numbering only 11 individuals in 2011, with few breeding females and a high risk of inbreeding (Shimada et al. 2009; Matsuzawa et al. 2011).

Bossou has long been considered an outlier when it comes to wild chimpanzee behavioural ecology and socio-ecology; however, this community still presents a unique model for wild chimpanzees living in a forest-agricultural mosaic and for advancing our understanding of chimpanzee behavioural and social flexibility in the face of local social, ecological and anthropogenic changes. The neighbouring Nimba Mountains are threatened with iron-mining in the northern region of the massif and further south on the Liberian side. Research on the Nimba chimpanzee population is therefore also crucial not only for their long-term survival and invaluable connection with the Bossou landscape, but also for yielding important insights into the impact of mining on chimpanzees across a transboundary mountain range. Information is urgently needed concerning their ranging, demography, genetics, health, feeding ecology, patterns of dispersal and responses to anthropogenic pressures, and how behavioural innovations and their transmission are potentially influenced by habitat change. We also need to better comprehend trends in threats, attitudes and behaviour towards chimpanzees in the region in light of impending development and influx of people into the area. Such human demographic changes have dramatically challenged the traditional cultural beliefs held by the local Manon people that until recently helped sustain a positive co-existence between people and chimpanzees, and that attracted Japanese primatologists' interest in this site. The deterioration of people's attitudes towards chimpanzees as a result of these rapid local socio-cultural shifts is deeply concerning. However, we hope that through collaborative efforts with local people and national and international partners, and an interdisciplinary approach, we will be able to conserve this emblematic chimpanzee population, combining natural and social science methodologies with basic and applied research objectives.

\section{Acknowledgments}

I would like to thank the Ministère de 1'Enseignement Supérieur et de la Recherche Scientifique et Technologique, in particular the Direction Nationale de la Recherche Scientifique et Technologique and 1'Institut de Recherche Environnementale de Bossou (IREB), for granting me the 
permission to carry out research at Bossou. I would like to thank Prof. N'Guessan Yoa Thomas, Director of Research of the "Ministère de l'Enseignement Supérieur et de la Recherche Scientifique", and Cdt. Sombo, Director of National Parks, and Capitaine Cisse, Director of the Nimba Reserve, from the "Ministère de l'Environnement et des Forêts" of Côte d'Ivoire, for granting me permission to work in Yealé in the Nimba Mountains between 1999 and 2001. I am particularly grateful to Tetsuro Matsuzawa, Jim Anderson, Charles Snowdon, Gen Yamakoshi and William McGrew for their advice and support, and to Caspar Schöning, Kathelijne Koops, Gaku Ohashi, Yasmin Möbius, and all the local assistants at Bossou, Seringbara and Yealé for their invaluable contributions and collaboration. Finally, I would like to acknowledge the financial support of the Ministry of Education, Science, and Culture, Japan (nos. 07102010, 12002009, and 10CE2005 to T. Matsuzawa), a Leakey Foundation Grant and an NIH Kirschstein-NRSA Postdoctoral Fellowship (no. MH06890601) to TH.

\section{References}

Adam JG (1981) Flore Descriptive des Monts Nimba, Côte d'Ivoire, Guinée, Libéria. CNRS, Paris, France

Angel F, Guibé J, Lamotte M (1954a) Lézards. La Réserve Intégrale du Mont Nimba, II Mémoire de l'Institut Français d'Afrique Noire 40:371380

Angel F, Guibé J, Lamotte M (1954b) Serpents. La Réserve Intégrale du Mont Nimba, II Mémoire de l'Institut Français d'Afrique Noire 40:381402

Baldwin PJ, Sabater Pi J, McGrew WC, Tutin CEG (1981) Comparisons of nests made by different populations of chimpanzees (Pan troglodytes). Primates 22:474-486

Biro D, Carvalho S, Matsuzawa T (2010) Tools, traditions, and technologies: Interdisciplinary approaches to chimpanzee nut-cracking. In: Lonsdorf EV, Ross SR, Matsuzawa T (eds) The mind of the chimpanzee. The University of Chicago Press, Chicago, pp 141-155 
Boesch C (1991) Handedness in wild chimpanzees. Int J Primatol $12: 541-558$

Boesch C, Boesch H (1983) Optimisation of nut cracking with natural hammers by wild chimpanzees. Behaviour 83:265-286

Boesch C, Marchesi P, Marchesi N, Fruth B, Joulian F (1994) Is nutcracking in wild chimpanzees a cultural behaviour? J Hum Evol $26: 325-338$

Collins DA, McGrew WC (1987) Termite fauna related to differences in tool-use between groups of chimpanzees (Pan troglodytes). Primates 28:457-471

Collins DA, McGrew WC (1988) Habitats of three groups of chimpanzees (pan troglodytes) in western Tanzania compared. J Hum Evol 17:553-574

de Waal F (2001) The ape and the sushi master: cultural reflections by a primatologist. Basic Books, New York

Gauthier-Hion A, Duplantier JM, Quris R, Feer F, Sourd C, Decoux JP, Dubost G, Emmons L, Erard C, Heckestweiler P, Moungazi A, Roussilhon C, Thiollay JM (1985) Fruit characters as a basis of food choice and seed dispersal in a tropical forest vertebrate community. Oecologia 65:324-337

Granier N, Hambuckers A, Matsuzawa T, Huynen MC (2014) Density estimates and nesting-site selection in chimpanzees of the Nimba Mountains, Cote d'Ivoire, and Guinea. Am J Primatol 76:999-1010. doi:10.1002/ajp.22278

Heim de Balsac H, Lamotte M (1958) Mammifères Rongeurs (Muscardinides et Murides). La Réserve Intégrale du Mont Nimba, IV Mémoire de 1'Institut Français d'Afrique Noire 53:339-357

Humle T (2003) Culture and variation in wild chimpanzee behaviour: a study of three communities in West Africa. University of Stirling 
Humle T (2010) How are army ants shedding new light on culture in chimpanzees? In: Lonsdorf EV, Ross S, Matsuzawa T (eds)

Understanding chimpanzees: the mind of the chimpanzee: ecological and experimental perspectives. Chicago University Press, Chicago, pp $116-126$

Humle T, Matsuzawa T (2001) Behavioural diversity among the wild chimpanzee populations of Bossou and neighbouring areas, Guinea and Cote d'Ivoire, West Africa-a preliminary report. Folia Primatol 72:5768. doi:10.1159/000049924

Humle T, Matsuzawa T (2002) Ant dipping among the chimpanzees of Bossou, Guinea, and comparisons with other sites. Am J Primatol 58:133-148

Humle T, Matsuzawa T (2004) Oil palm use by adjacent communities of chimpanzees at Bossou and Nimba Mountains, West Africa. Int J Primatol 25:551-581. doi:10.1023/B:IJOP.0000023575.93644.f4

Humle T, Matsuzawa T (2009) Laterality in hand use across four tooluse behaviors among the wild chimpanzees of Bossou, Guinea, West Africa. Am J Primatol 71:40-48. doi:10.1002/ajp.20616

Humle T, Newton-Fisher NE (2013) Culture in non-human primates: definitions and evidence In: Ellen R, Lycett S, Johns S (eds) Understanding Cultural Transmission Berghahn Books

Humle T, Snowdon CT, Matsuzawa T (2009) Social influences on antdipping acquisition in the wild chimpanzees (Pan troglodytes verus) of Bossou, Guinea, West Africa. Animal Cognition 12:S37-S48. doi:10.1007/s10071-009-0272-6

Inoue-Nakamura N, Matsuzawa T (1997) Development of stone tool use by wild chimpanzees (Pan troglodytes). J Com Psychol 111:159-173

Joulian F (1994) Culture and material culture in chimpanzees and early hominids. In: Roeder JJ, Thierry B, Anderson JR, Herrenschmidt N (eds) Current primatology, vol II., Social development. learning and behaviourUniversité Louis Pasteur, Strasbourg, pp 397-404 
Koops K, Humle T, Matsuzawa T, Sterck EHM (2004) Terrestrial nesting in the chimpanzees of Nimba Mountains, Guinea, West Africa: environmental or social? Folia Primatol 75:387

Koops K, Humle T, Sterck EHM, Matsuzawa T (2007) Ground-nesting by the chimpanzees of the Mimba Mountains, Guinea: environmentally or socially determined? Am J Primatol 69:407-419. doi:10.1002/ajp.20358

Koops K, Humle T, Sterck EHM, Matsuzawa T (2008) Ground-nesting in the chimpanzees (Pan troglodytes verus) of the Nimba Mountains, Guinea, West Africa: new findings. Folia Primatol 79:346

Koops K, Schoning C, Isaji M, Hashimoto C (2015a) Cultural differences in ant-dipping tool length between neighbouring chimpanzee communities at Kalinzu, Uganda. Sci Rep 5. toi:12456doi: $10.1038 /$ srep 12456

Koops K, Schoning C, McGrew W, Matsuzawa T (2015b) Chimpanzees Prey on Army Ants at Seringbara, Nimba Mountains, Guinea: predation patterns and tool use characteristics. Am J Primatol 77:319-329. doi:10.1002/ajp.22347

Kortlandt A (1962) Chimpanzees in the wild. Sci Am 206:128-138

Kortlandt A (1986) The use of stone tools by wild living chimpanzees and earliest hominids. J Hum Evol 15:77-132

Lacreuse A, Parr LA, Smith HM, Hopkins WD (1999) Hand preferences for a haptic task in chimpanzees (Pan troglodytes). Int J Primatol $20: 867-881$

Leclerc JC, Lamotte M, Richard-Molard J, Rougerie G, Porteres P (1955) La Chaine du Nimba: Essai Géographique. La Réserve Intégrale du Mont Nimba, III Mémoire de l'Institut Français d'Afrique Noire (IFAN, Dakar, Sénégal) 43:1-256

Marchant LF, McGrew WC (1996) Laterality of limb function in wild chimpanzees of Gombe National Park: comprehensive study of 
spontaneous activiities. J Hum Evol 30:427-443

Marchant LF, McGrew WC, Eibleibesfeldt I (1995) Is Humaandedness Universal - Ethological Analyses From 3 Traditional Cultures. Ethology $101: 239-258$

Matsuzawa T, Yamakoshi G (1996) Comparison of chimpanzee material culture between Bossou and Nimba, West Africa. In: Russon AE, Bard K, Parker ST (eds) Reaching into Thought. Cambridge University Press, Cambridge, pp 211-232

Matsuzawa T, Biro D, Humle T, Inoue-Nakamura N, Tonooka R, Yamakoshi G (2001) Emergence of culture in wild champanzees: Education by master-apprenticeship. Primate origins of human cognition and behavior

Matsuzawa T, Humle T, Sugiyama Y (2011) Chimpanzees of Bossou and Nimba. Springer Verlag, Tokyo

McGrew WC (1979) Evolutionary implications of sex differences in chimpanzee predation and tool use. In: Hamburg DA, McCrown ER (eds) The Great Apes. Benjamin Cummings, London, pp 441-463

McGrew WC (1992) Chimpanzee Material Culture: Implications for Human Evolution. Cambridge University Press, Cambridge

McGrew WC, Marchant LF (2001) Ethological study of manual laterality in the chimpanzees of the Mahale Mountains, Tanzania. Behaviour 138:329-358

McGrew WC, Ham RM, White LJT, Tutin CEG, Fernandez M (1997) Why don't chimpanzees in Gabon crack nuts? Int J Primatol 18:353374

Mobius Y, Boesch C, Koops K, Matsuzawa T, Humle T (2008) Cultural differences in army ant predation by West African chimpanzees? A comparative study of microecological variables. Anim Behav 76:37-45. doi:10.1016/j.anbehav.2008.01.008 
Mollard R, Lamotte M, Portieres R (1955) La Chaine du Nimba: les conditions climatiques. La Réserve Intégrale du Mont Nimba. III Mémoire de l'Institut Français d'Afrique Noire (IFAN) 43:59-115

Nakamura M, Nishida T (2006) Subtle behavioral variation in wild chimpanzees, with special reference to Imanishi's concept of kaluchua. Primates 47:35-42

Nishida T, Wrangham RW, Goodall J, Uehara S (1983) Local differences in plant-feeding habits of chimpanzees between the Mahale Mountains and Gombe National Park. J Hum Evol 12:467-480

Ohashi $G$ (2015) Pestle-pounding and nut-cracking by wild chimpanzees at Kpala, Liberia. Primates 56:113-117. doi:10.1007/s10329-015-0459-1

Schoning C, Humle T, Mobius Y, McGrew WC (2008) The nature of culture: technological variation in chimpanzee predation on army ants revisited. J Human Evol 55:48-59. doi:10.1016/j.jhevol.2007.12.002

Shimada M (2000) A survey of the Nimba Mountains, West Africa from three routes: confirmed new habitat and ant catching wand use of chimpanzees. Pan Africa News 7:7-10

Shimada M, Hayakawa S, Humle T, Fujita S, Hirata S, Sugiyama Y, Saitou N (2004) Mitochondrial DNA genealogy of chimpanzees in the Nimba Mountains and Bossou, West Africa. Am J Primatol 64:261-275. doi:10.1002/ajp.20077

Shimada M, Hayakawa S, Fujita S, Sugiyama Y, Saitou N (2009) Skewed Matrilineal Genetic Composition in a Small Wild Chimpanzee Community. Folia Primatol 80:19-32

Sousa C, Biro D, Matsuzawa T (2009) Leaf-tool use for drinking water by wild chimpanzees (Pan troglodytes): acquisition patterns and handedness. Animal Cognition 12:S115-S125. doi:10.1007/s10071-0090278-0

Sugiyama Y (1981) Observations on the population dynamics and 
behavior of wild chimpanzees at Bossou, Guinea, 1979-1980. Primates 22:435-444

Sugiyama Y (1995) Tool-use for catching ants by chimpanzees at Bossou and Monts Nimba. Primates 36:193-205

Sugiyama Y, Koman J (1979a) Social structure and dynamics of wild chimpanzees at Bossou, Guinea. Primates 20:323-339

Sugiyama Y, Koman J (1979b) Tool-using and -making behavior in wild chimpanzees at Bossou, Guinea. Primates 20:513-524

Sugiyama Y, Fushimi T, Sakura O, Matsuzawa T (1993) Hand preference and tool-use in wild chimpanzees. Primates 34:151-159

Toth N (1985) Archaeological evidence for preferential right handedness in the lower and middle Pleistocene, and its possible implications. J Hum Evol 14:607-614

Uehara S (1982) Seasonal changes in the techniques employed by wild chimpanzees in the Mahale Mountains, Tanzania, to feed on termites (Pseudacanthotermes spiniger). Folia Primatol 37:44-76

Warren JM (1980) Handedness and laterality in humans and other animals. Physiological Psychology 8(351):359

Yamakoshi G (1998) Dietary responses to fruit scarcity of wild chimpanzees at Bossou, Guinea: possible implications for ecological importance of tool-use. Am J Phys Anthropol 106:283-295

Yamakoshi G, Sugiyama Y (1995) Pestle-pounding behavior of wild chimpanzees at Bossou, Guinea: a newly observed tool-using behavior. Primates 36:489-500 